\title{
Remote sensing-based artificial surface cover classification in Asia and spatial pattern analysis
}

\author{
KUANG WenHui $^{1 *}$, CHEN LiJun $^{2}$, LIU JiYuan ${ }^{1}$, XIANG WeiNing $^{3,4}$, CHI WenFeng ${ }^{1}$, \\ LU DengSheng ${ }^{5,6}$, YANG TianRong ${ }^{1,8}$, PAN Tao ${ }^{7,8}$ \& LIU AiLin ${ }^{1,8}$ \\ ${ }^{1}$ Key Laboratory of Land Surface Pattern and Simulation, Institute of Geographic Sciences and Natural Resources Research, \\ Chinese Academy of Sciences, Beijing 100101, China; \\ ${ }^{2}$ National Geomatics Center of China, Beijing 100830, China; \\ ${ }^{3}$ School of Ecological and Environmental Sciences, East China Normal University, Shanghai 200241, China; \\ ${ }^{4}$ University of North Carolina at Charlotte, NC 28223, USA; \\ ${ }^{5}$ School of Environmental \& Resource Sciences, Zhejiang A\&F University, Hangzhou 311300, China; \\ ${ }^{6}$ Michigan State University, East Lansing, MI 48823, USA; \\ ${ }^{7}$ State Key Laboratory of Desert and Oasis Ecology, Xinjiang Institute of Ecology and Geography, Chinese Academy of Sciences, \\ Urumqi 830011, China: \\ ${ }^{8}$ College of Resources and Environment, University of Chinese Academy of Sciences, Beijing 100049, China
}

Received September 24, 2015; accepted February 16, 2016; published online April 26, 2016

\begin{abstract}
Artificial surfaces, characterized with intensive land-use changes and complex landscape structures, are important indicators of human impacts on terrestrial ecosystems. Without high-resolution land-cover data at continental scale, it is hard to evaluate the impacts of urbanization on regional climate, ecosystem processes and global environment. This study constructed a hierarchical classification system for artificial surfaces, promoted a remote sensing method to retrieve subpixel components of artificial surfaces from 30-m resolution satellite imageries (GlobeLand30) and developed a series of data products of high-precision urban built-up areas including impervious surface and vegetation cover in Asia in 2010. Our assessment, based on multisource data and expert knowledge, showed that the overall accuracy of classification was $90.79 \%$. The mean relative error for the impervious surface components of cities was 0.87 . The local error of the extracted information was closely related to the heterogeneity of urban buildings and vegetation in different climate zones. According to our results, the urban built-up area was $18.18 \times 10^{4} \mathrm{~km}^{2}$, accounting for $0.59 \%$ of the total land surface areas in Asia; urban impervious surfaces were $11.65 \times 10^{4} \mathrm{~km}^{2}$, accounting for $64.09 \%$ of the total urban built-up area in Asia. Vegetation and bare soils accounted for $34.56 \%$ of the urban built-up areas. There were three gradients: a concentrated distribution, a scattered distribution and an indeterminate distribution from east to west in terms of spatial pattern of urban impervious surfaces. China, India and Japan ranked as the top three countries with the largest impervious surface areas, which respectively accounted for $32.77 \%, 16.10 \%$ and $11.93 \%$ of the urban impervious surface area of Asia. We found the proportions of impervious surface and vegetation cover within urban built-up areas were closely related to the economic development degree of the country and regional climate environment. Built-up areas in developed countries had relatively low impervious surface and high public green vegetation cover, with 50-60\% urban impervious surfaces in Japan, South Korea and Singapore. In comparison, the proportion of urban impervious surfaces in developing countries is approaching or exceeding $80 \%$ in Asia. In general, the composition and spatial patterns of built-up areas reflected population aggregation and economic development level as well as their impacts on the health of the environment in the sub-watershed.
\end{abstract}

Keywords Artificial surface cover, City, Impervious surface, Vegetation cover, Remote sensing classification, Asia

*Corresponding author (email: kuangwh@igsnrr.ac.cn) 
Citation: Kuang W H, Chen L J, Liu J Y, Xiang W N, Chi W F, Lu D S, Yang T R, Pan T, Liu A L. 2016. Remote sensing-based artificial surface cover classification in Asia and spatial pattern analysis. Science China Earth Sciences, 59: 1720-1737, doi: 10.1007/s11430-016-5295-7

\section{Introduction}

The impacts of human activities on ecological, environmental and climatic systems at local and regional scales are intensive and extensive (Messerli et al., 2000; Zhang et al., 2008; Lu, 2014). The strategic framework of Future Earth (www.futureearth.org) emphasizes global sustainable research, focuses on the observation, interpretation, understanding and prediction of the driving forces and processes that govern the dynamics of biogeochemical, environmental and social systems of the earth. One of challenges is to find a way to shape and build healthy, flexible and efficient cities through the improvement of urban environments and the reduction of urban footprints on resource consumption (www.futureearth.org). Land-use and land-cover changes directly reflect the impact of human activities on the terrestrial environment at regional to global scales (Zhang et al., 2012, 2014). For example, land-use and land-cover changes affect biogeophysical and biogeochemical processes, the surface radiation energy balance, carbon budget and even surface water circulation (Sterling et al., 2013; Boysen et al., 2014; Zhang et al., 2014; Yan et al., 2015). An increase in the impervious surface area will affect local and regional climates, aggravate the effect of urban heat islands and bring pollution to water environments (Arnold and Gibbons, 1996; Grimmond, 2007; Grimm et al., 2008; Bierwagen et al., 2010; Zhao et al., 2014; Kuang et al., 2015a, 2015b; Yan et al., 2016).

Built-up areas and impervious surfaces are important indicators of the degree of development and urbanization level of a city. Elvidge et al. (2007) used nighttime light index data from the Defense Meteorological Satellite Program Operational Linescan System (DMSP-OLS) to develop 1-km impervious surfaces data for the built-up land of the world. They estimated that the global impervious surface area in 2000 was $57.97 \times 10^{4} \mathrm{~km}^{2}$, accounting for $0.43 \%$ of the world's total land surface area. Schneider et al. (2009) extracted the urban areas using 500-m resolution Moderate Resolution Imaging Spectroradiometer (MODIS) data from 2001 to 2002 and assessed the global urban land area to be $65.70 \times 10^{4} \mathrm{~km}^{2}$. The U.S. Geological Survey (USGS) used Landsat Thematic Mapper (TM) data to develop a 30-m resolution national impervious surface dataset based on a national land-cover database (Yang et al., 2003; Xian and Homer, 2010). Based on a dataset of land-use and landcover changes in China, Kuang et al. (2013) used the
MODIS normalized difference vegetation index (NDVI) and DMSP-OLS data to develop a settlement index to monitor the changes in urban expansion and impervious surface areas in an eight-year period in the early 21 st century (Lu et al., 2008; Kuang, 2012a, 2012b; Kuang et al., 2013). Medium spatial-resolution remote sensing images (e.g., Landsat TM, HJ-1A/1B, etc.) were mainly used to monitor impervious surface areas in urban agglomerations or specific urban zones (Zhang et al., 2015a).

Although a number of researchers have estimated that urban land areas account for 1-3\% of the total land surface area (Liu Z F et al., 2014), the percentage of the total global land surface occupied by urban land is still not clear. Because of inconsistencies in the definitions of the scientific concepts and classification systems, and differences in data sources and methods, previous studies presented relatively large differences in urban land classification results. When using remote sensing images to monitor land-use and landcover changes, the 30-m resolution Landsat TM/enhanced TM (ETM+) images are considered the optimal scale for landscape studies (Liu J Y et al., 2010, 2014; Chen et al., 2014a, 2014b, 2015). While considering the internal landcover composition in urban areas, even a $30-\mathrm{m}$ spatial resolution cannot avoid mixed pixels (Lu et al., 2014a; Kuang et al., 2014; Zhang et al., 2015b). Based on 30-m-resolution Landsat TM/ETM+ images, Kuang et al. (2013, 2014) evaluated the differences in the spatiotemporal characteristics of the impervious surface areas in six mega cities in China and the USA. They found that the proportions of impervious surface areas fell in the range of $60-83 \%$ in the Chinese cities, and in the range of $45-78 \%$ in the U.S. cities. Another study has shown that the urban landscapes in the USA are mostly embedded with impervious surfaces and trees (Nowak and Greenfield, 2012). Therefore, using 500-m-resolution MODIS remote sensing images to map an urban area will reduce the precision of the urban land classification estimation of urban areas.

In 2009, China took the lead in high-precision remote sensing mapping of the global land surface and developed the first 30-m-resolution global surface cover product (GlobeLand30) using Landsat TM and HJ-1A remote sensing data. The overall classification accuracy of 10 cases of global Level I surface cover type was over $80 \%$, and user precision of the artificial surface cover classification was 86.7\% (Cao et al., 2014; Chen et al., 2014b, 2015; Liao et al., 2014). In current studies, effective remote sensing detection methods for artificial surface cover and high- 
precision artificial surface cover products are crucial for further studies in the urbanization effects on regional climate, ecological system processes and global environmental change. There are three basic remote sensing classification methods for urban impervious surfaces: man-machine interactive interpretation, the application of spectral characteristics and the application of models (Slonecker et al., 2001). In recent years, important progress has been made in the research on developing new technical methods for extracting urban impervious surface information. The main methods include the pixel-by-pixel image classification method (Hodgson et al., 2003), the neural network method (Hu and Weng, 2009), the regression tree models (Yang et al., 2003; Xian and Crane, 2005) and the mixed pixel decomposition method (Lu and Weng, 2004; Zhang et al., 2015a). Those methods have been successfully used at city, urban agglomeration and national scales (Lu et al., 2014a; Yan et al., 2016). Therefore, it is highly feasible and realistic to expand the remote sensing classification of artificial cover surface and urban impervious surface components to the intercontinental scale through the fusion of multisource remote sensing data and integration of the aforementioned key technical methods.

Compared with other regions in the world, Asia is undergoing rapid urban population concentration and urban sprawl. Asia's urban population in 2010 accounted for $43 \%$ of the global urban population and is expected to reach $63 \%$ by 2050 , forming a region with extremely large cities and urban agglomerations with populations in the tens of millions. Over the past 30 years, the urbanization process in Asia has been accelerating, which has resulted in a series of environmental problems such as urban air pollution, flooding, drought and aggravated heat island effects. Therefore, this study aimed to propose a concept model of the internal structures of cities, design a surface hierarchical structure classification system, improve the classification techniques for artificial surface extraction, and identify urban built-up areas in Asia using multisource remote sensing data based on GobeLand30 data. Moreover, we studied the spatiotemporal relationship between economy and urban land structure in different countries. The research results can provide important information for the construction of healthy living environments and sustainable development strategies for Asian cities, and the implementation of the One Belt and One Road initiative.

\section{Data sources and study methods}

\subsection{Study area and dataset}

Asia was chosen as the study area (Figure 1), and 48 countries were investigated, including five countries in East Asia (China, Japan, North Korea, South Korea and Mongolia), 11 countries in Southeast Asia (e.g., Vietnam, the Philippines,
Singapore), 17 countries in South Asia (e.g. India, Bangladesh, Indonesia), five countries in Central Asia (Kazakhstan, Kyrgyzstan, Tajikistan, Uzbekistan and Turkmenistan) and 17 countries in West Asia (e.g. Afghanistan, Iran, Iraq). Asia has a total land area of $3072 \times 10^{4} \mathrm{~km}^{2}$ and accounts for one-fifth of the total global land area. Because Russia stretches over the European and Asian continents, and its population and property are mostly concentrated in the western region, Russia was not included in the study area. The data sources mainly included the 2010 GlobeLand 30 30-m global surface cover map (www.globeland30.org), the European Space Agency (ESA) global land-cover dataset for 2008-2012 (http://maps.elie.ucl.ac.be), the 2010 MODIS NDVI 16-d 250-m synthetic data, the 2010 1-km DMSP-OLS nighttime light index data (http://ngdc.noaa. gov/eog/dmsp/downloadV4composites.html) and the 2010 Landsat TM images downloaded from the USGS website (http://glovis.usgs.gov/). The sub-watershed distribution data was obtained from the watershed boundaries extracted from the 1-km USGS digital elevation model. Regional data included the 1:100000 vector data of the land-use and land-cover conditions of China in 2010. The verification samples were obtained from high-resolution image data for 2010 downloaded from Google Earth. The details of data sources are shown in Table 1.

\subsection{Definition of the classification system}

To scientifically measure the spatiotemporal range and distribution characteristics of artificial surfaces, we created a three-level classification system that included the following components: artificial surface cover; urban built-up area and its internal components (impervious surface area, green space, water, etc.). Artificial surface cover refers to artificial ecosystems composed of biological and non-biological environments in urban and rural construction land, industrial land and mining land. They include town, rural residential buildings, independent industrial land and vegetation and water bodies within the basic mapping unit. In detail, urban built-up areas include the following cover types: impervious surface, water body, vegetation and bare soils; impervious surface areas are primarily composed of building roofs, cement and asphalt roads, marble squares and concrete. Impervious surface is the main land-cover type in urban built-up areas (Kuang, 2012b, 2012c; Kuang et al., 2014; Lu et al., 2014b; Liu Z F et al., 2014). Urban green space is the main type of urban vegetation, and significantly seasonal differences are observed in certain temperate and cold zones, with vegetation flourishing in summer and withering in winter. After the vegetation has withered, the surface area covered by vegetation is displayed as bare soil in images. Because of the seasonal aspect of Landsat TM and HJ-1A images, this study classified highly mixed vegetation and bare soil as urban vegetation, which primarily includes lawn, trees and a small amount of bare soil (Figure 2). 


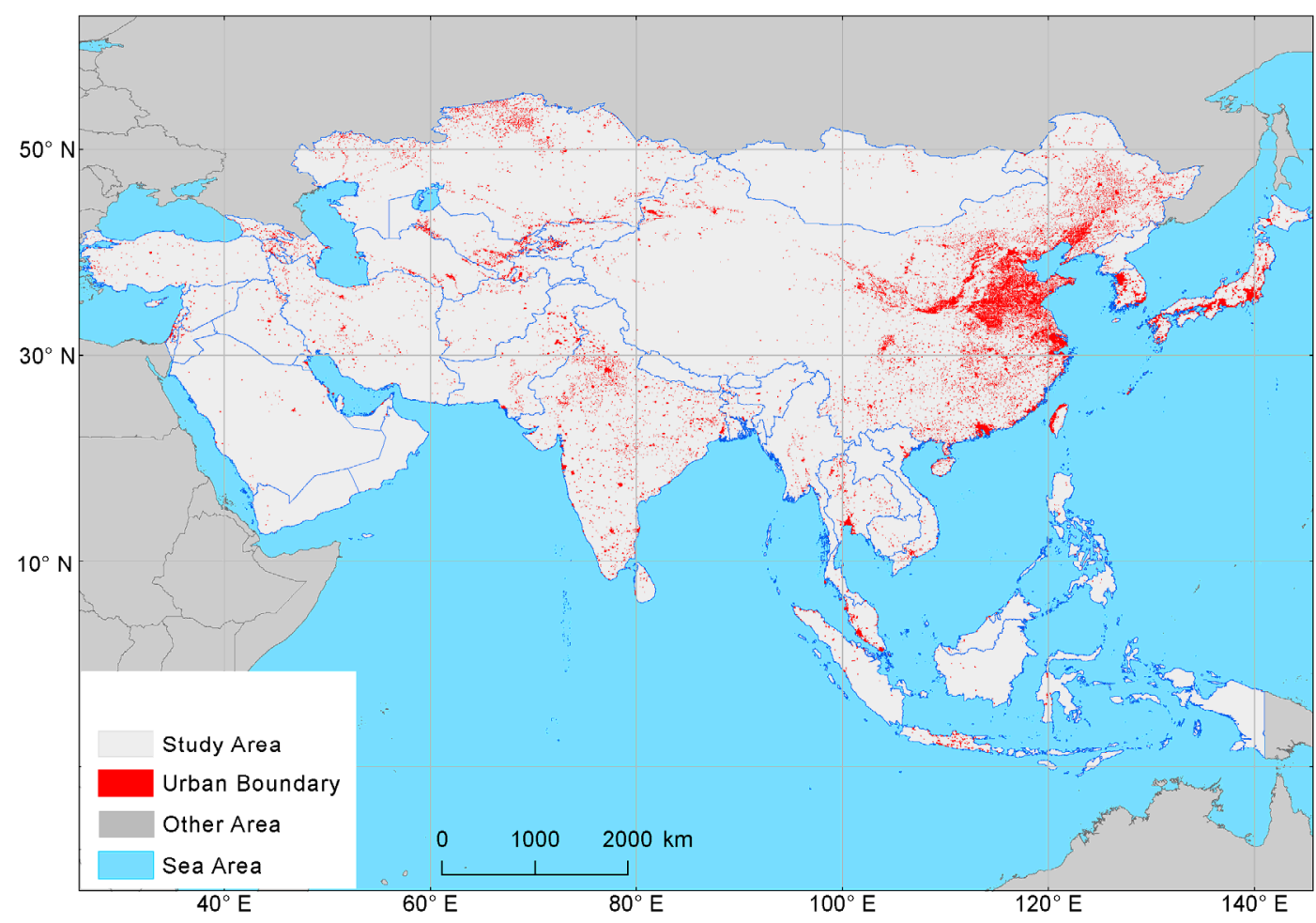

Figure 1 Distribution map of the study area.

Table 1 Detailed information for the data sources

\begin{tabular}{|c|c|c|c|c|}
\hline Data type & Name & Resolution and data type & Data source & Function \\
\hline \multirow{5}{*}{ Basic Data } & GlobeLand30 & $\begin{array}{l}\text { 30-m-resolution raster } \\
\text { data }\end{array}$ & www.globeland30.org & $\begin{array}{l}\text { To obtain } 30-\text { m-resolution Level I data on artificial } \\
\text { surface cover and accurately determine urban and } \\
\text { rural boundary information }\end{array}$ \\
\hline & MODIS NDVI & $\begin{array}{l}250-\text { m-resolution syn- } \\
\text { thetic raster data of } 16 \\
\text { days }\end{array}$ & http://modis.gsfc.nasa.gov/ & $\begin{array}{l}\text { To classify information on internal structures of } \\
\text { cities and reflect the conditions of the urban green } \\
\text { lawn and tree components }\end{array}$ \\
\hline & DMSP-OLS & $\begin{array}{l}\text { 1-km-resolution raster } \\
\text { data }\end{array}$ & http://ngdc.noaa.gov & $\begin{array}{l}\text { To classify information on internal structures of } \\
\text { cities and reflect the urban boundary distribution } \\
\text { and the conditions of impervious surface compo- } \\
\text { nents of cities }\end{array}$ \\
\hline & $\begin{array}{l}\text { ESA's global } \\
\text { land-cover data }\end{array}$ & $\begin{array}{l}\text { 300-m-resolution raster } \\
\text { data }\end{array}$ & http://maps.elie.ucl.ac.be & $\begin{array}{l}\text { To calibrate the urban boundary information and } \\
\text { obtain urban vegetation and water information } \\
\text { from GlobeLand30 }\end{array}$ \\
\hline & Landsat TM & $\begin{array}{l}\text { 30-m-resolution recti- } \\
\text { fied images }\end{array}$ & http://glovis.usgs.gov/ & $\begin{array}{l}\text { To obtain higher-precision data on the impervious } \\
\text { surface and green space components of typical cit- } \\
\text { ies and correct the } 250-\mathrm{m} \text {-resolution data of the } \\
\text { impervious surface and green space components }\end{array}$ \\
\hline \multirow[t]{2}{*}{ Ancillary data } & $\begin{array}{l}\text { Current situation of } \\
\text { land use/cover in } \\
\text { China }\end{array}$ & $\begin{array}{l}\text { 30-m-resolution raster } \\
\text { data }\end{array}$ & $\begin{array}{l}\text { Institute of Geographic Sciences } \\
\text { and Natural Resources Research, } \\
\text { Chinese Academy of Sciences }\end{array}$ & $\begin{array}{l}\text { To obtain artificial surface cover level-type segmen- } \\
\text { tation thresholds and determine urban boundaries }\end{array}$ \\
\hline & $\begin{array}{c}\text { Sub-watershed } \\
\text { boundaries }\end{array}$ & Vector boundaries & http://webgis.wr.usgs.gov & $\begin{array}{l}\text { To analyze the level of the proportion of impervious } \\
\text { surfaces in each sub-watershed in Asia }\end{array}$ \\
\hline Reference data & Google Earth & $\begin{array}{l}\text { High-resolution rectified } \\
\text { images }\end{array}$ & http://google-earth.en.softonic.com/ & $\begin{array}{l}\text { To evaluate data precision and high-precision image } \\
\text { sources in the areas of classification accuracy and } \\
\text { component proportion error }\end{array}$ \\
\hline
\end{tabular}

\subsection{Remote sensing image classification}

A fine subclass classification of artificial surface cover is needed to perform scientific spatial measurements and meet the monitoring requirements of urban surface structures and ecological regulations. GlobeLand30 has 10 types at Level I, in which artificial cover mainly includes urban built-up areas (excluding urban vegetation, water bodies and bare soil), rural residential land and lands for traffic, industry and mining construction. In reality, the pixels in 30-m cell size 


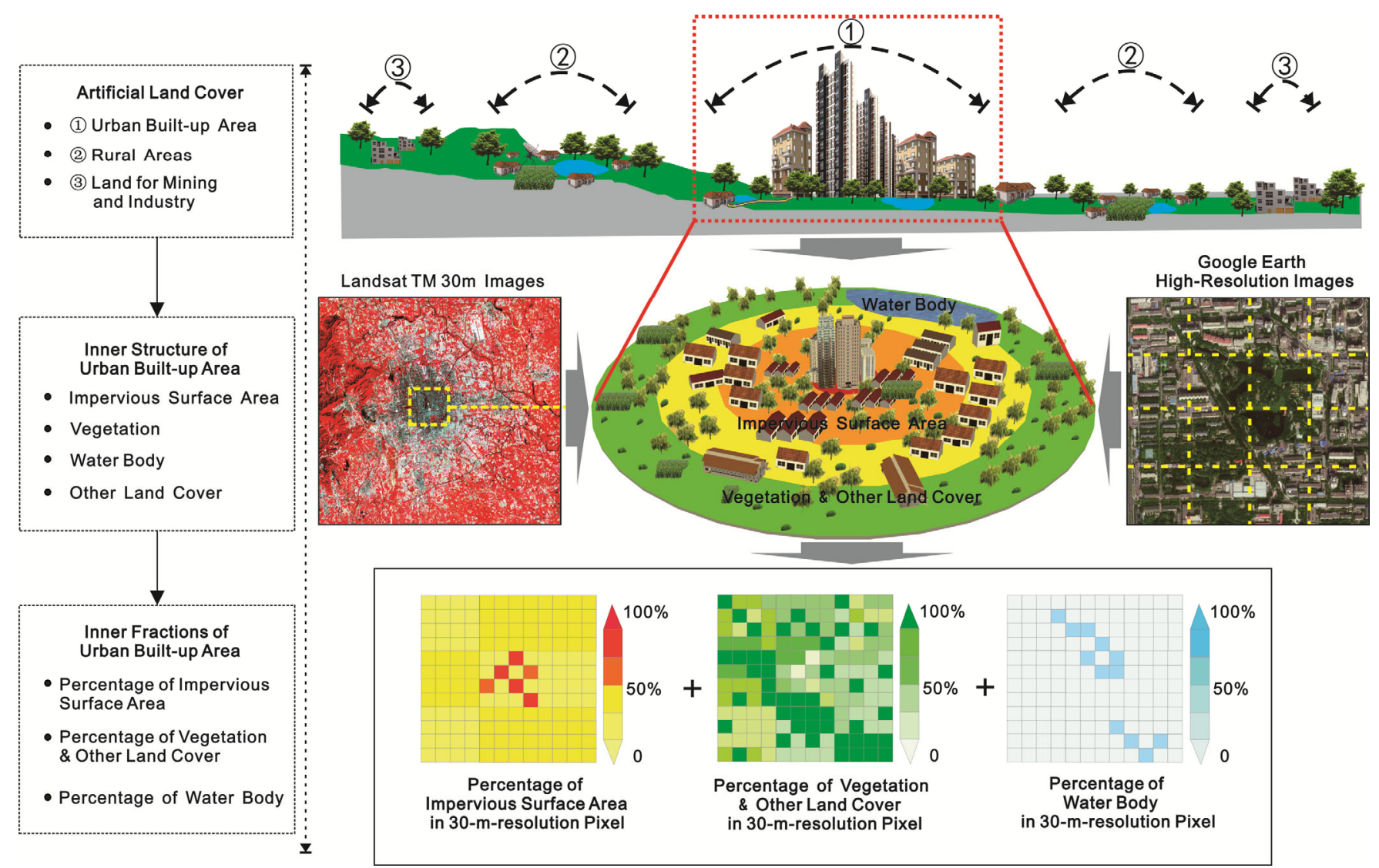

Figure 2 Schematic diagram for the artificial land cover classification system and the internal component structures of the urban built-up area.

often contain impervious surface, vegetation and bare soil at proportions ranging from 0 to $100 \%$-no impervious surfaces to completely be covered by impervious surfaces (Figure 2). Therefore, the 30-m spatial range of artificial cover on urban land, extracted directly from the GlobeLand30 product, is smaller than the range of urban built-up area but larger than that of urban impervious surface area. Thus, this study was conducted to perform a fine classification of artificial surface cover, which is specifically divided into four steps: (1) obtaining complete information on artificial cover at a 30-m resolution based on the multisource data fusion method; (2) correcting the artificial cover boundary information with expert knowledge through comparisons of the corrected Landsat TM and HJ-1A images for 2010; (3) conducting pixel unmixing for the 30-m resolution information; (4) obtaining the fine classification results for artificial cover through spatial operations. Figures 2 and 3 illustrate the technical process.

Step 1: multisource data fusion. The GlobeLand30 product is subjected to data-formatting conversion, projection transformation and map combination. The ESA 300-m land-cover data (ESR GLC300), the MODIS NDVI 250-m data and the DMSP-OLS 1-km data are subjected to formatting conversion and projection transformation. The grid format is used for all data processing. The World Geodetic System 84 projection is used for mapping. Spatial opera- tions and statistical analysis for the area correspond to the Albers equal-area conic projection of the central median of each country. The 30-m Level I artificial surface cover type and the ESR GLC300 urban land type are extracted. Using ESR GLC300 as the spatial mask based on a pixel setting of 30-m, the total factor types of the GlobeLand30 product are extracted. Within the urban and rural construction land area, the forestlands and grasslands are used to represent the vegetation cover; the water bodies are used to represent the water bodies; and all other cover types are classified as other types. The 30-m resolution artificial surface cover extracted from the GlobeLand30 product is further merged with the ESR GLC300-masked vegetation, water bodies and other cover types to generate boundary information of the urban and rural constructions.

The MODIS NDVI 250-m data and DMSP-OLS 1-km data are used to produce the $250-\mathrm{m}$ building density (BD) index based on the following equation:

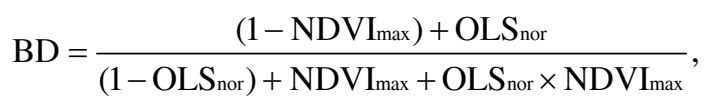

where BD represents the building density index, $\mathrm{NDVI}_{\max }$ represents the maximum value in annual MODIS NDVI and $\mathrm{OLS}_{\text {nor }}$ represents the normalized light index (0-1) (Lu et al., 2008; Kuang, 2012a; Kuang et al., 2013). 


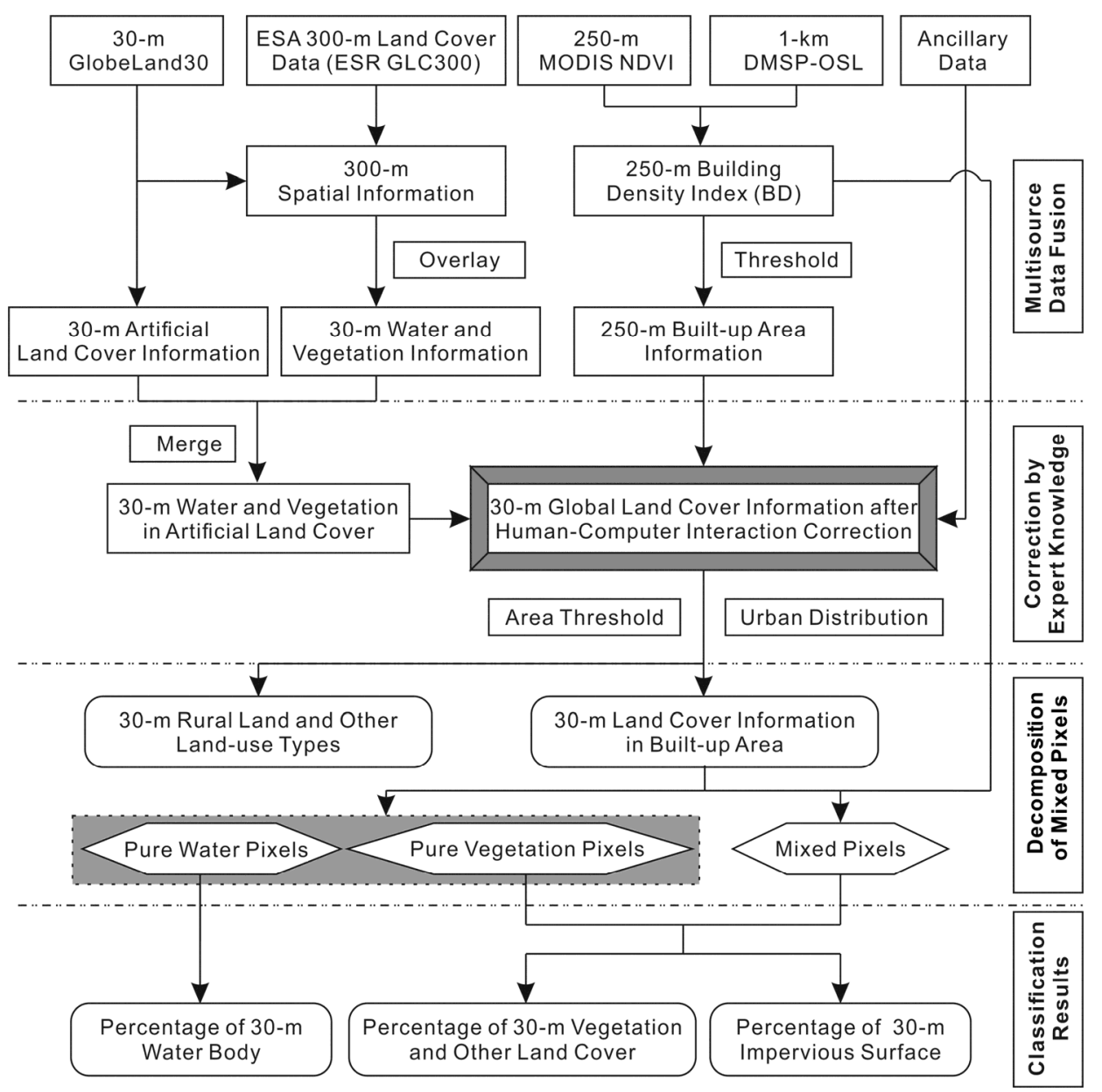

Figure 3 Flowchart of artificial land cover classification based on multisource data fusion.

The city boundary information, which was created from MODIS NDVI 250-m data, DMSP-OLS 1-km data and urban land types in ESR GLC300 are merged with the GlobeLand30 mask information, and this is followed by a spatial analysis to generate the 30-m resolution dataset for urban and rural construction land using multisource data fusion.

Step 2: revision of classification results using expert knowledge. The 30-m dataset of urban and rural construction land in Asia is converted to a vector format. Segmentation is performed based on the threshold value of polygon areas: polygons with an area bigger than $10 \mathrm{~km}^{2}$ are classified as cities. City boundaries are extracted and other cover types are finally classified as rural land-use type. The classification results are revised using the ArcGIS interface based on expert knowledge. This is followed by comparing the results with the Landsat TM and HJ-1A images of 2010, consulting information on the point distribution of cities and traversing the spatial information on all the urban and rural construction lands.

Step 3: decomposition of mixed pixels. The mixed pixels and pure pixels of impervious surface and vegetation are generated using the revised city boundary information
(GlobeLand30-Urban) and the GlobeLand30 product. The relationship between impervious surface obtained from decomposition of mixed pixels and the $250-\mathrm{m} \mathrm{BD}$ is established to obtain the proportion of urban impervious surface areas in mixed pixels.

Step 4: obtaining the accurate fine classification results of the subclass information in cities. The proportions of impervious surfaces (0-100) with $30-\mathrm{m}$ spatial resolution decomposed from mixed pixels are used in the final (GlobeLand30-Impervious) mapping results. A spatial summation is applied to the vegetation information decomposed from mixed pixels and the full urban vegetation cover information generated from the classification (100\%) is used to generate the final (GlobeLand30-Urban vegetation) mapping results (Figure 4).

\subsection{Evaluation of classification results}

The classification accuracy assessment in this research includes the evaluation of pixel-level classification results and the proportion of impervious surfaces or vegetation within the spatial distribution area. The classification accuracy assessment was conducted in two aspects: (1) overall accu- 

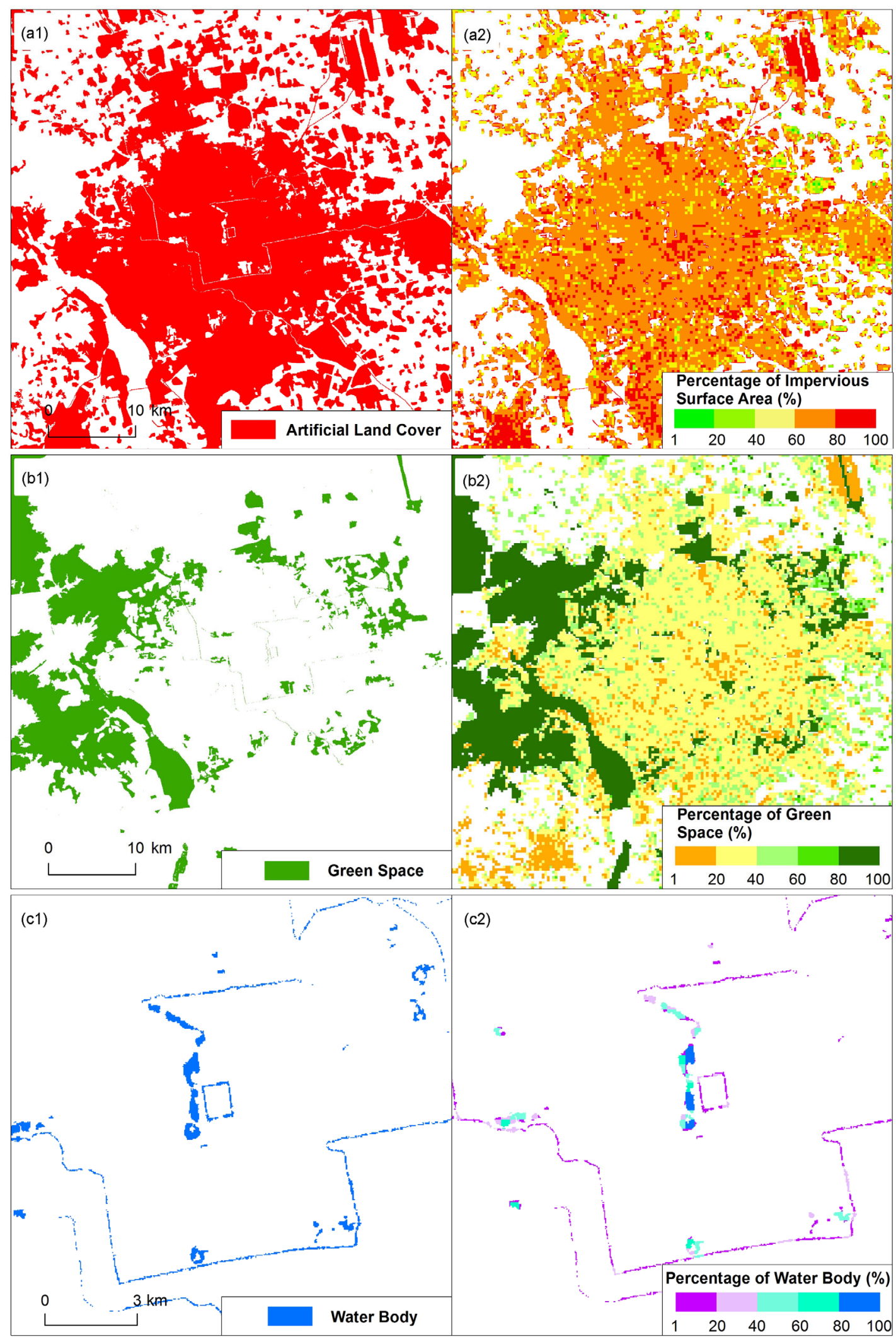

Figure 4 Fine classification results for artificial surface covers in Beijing, as an example. (a1) 30-m resolution information on artificial surface cover; (a2) 250-m resolution information on the proportion of urban impervious surfaces; (b1) 30-m resolution information on forestlands and grasslands; (b2) 250-m resolution information on the proportion of urban vegetation areas; (c1) 30-m resolution information on water bodies; (c2) 250-m resolution information on proportion of urban water areas. 
racy, producer's accuracy and user's accuracy for the pixel-level classification of the urban built-up areas and (2) correlation coefficients $\left(R^{2}\right)$ and mean relative errors (MREs) of internal components within the city. The classification results were verified using Google Earth images for 2010 using the hierarchical random sampling method. To reduce errors from image registration, a $3 \times 3(750 \mathrm{~m} \times 750$ m) pixel window was used for each sampling point, and finely corrected high-resolution images were both manually interpreted by experts and digitally interpreted to obtain information for the verification samples. A total of 2725 samples were obtained from various countries in Asia. The digitized proportions of impervious surfaces, vegetation, bare soils and water bodies were visually interpreted, and results were used to represent the true ground verification values (Figure 5).

The MRE value is used to evaluate the extracted impervious surface and vegetation components from each pixel based on the following equation:

$$
\operatorname{MRE}=\frac{\sum_{i=1}^{n}\left(\frac{\left|x_{i}-y_{i}\right|}{y_{i}}\right)}{n},
$$

where MRE represents the mean relative error; $x_{i}$ and $y_{i}$ represent the proportion of impervious surfaces from high-resolution images and ground-sampled components extracted from the $3 \times 3$ pixel, respectively; and $n$ represents the number of samples.

\subsection{Method of analyzing distribution characteristics}

To scientifically measure and map the artificial surface distribution pattern of Asia and compare the different artificial cover distribution characteristics within the continent, the distribution characteristics were analyzed at three scales: Asian continent scale, country scale and sub-watershed scale. The distribution intensity index of the artificial surface in a watershed is defined as follows:
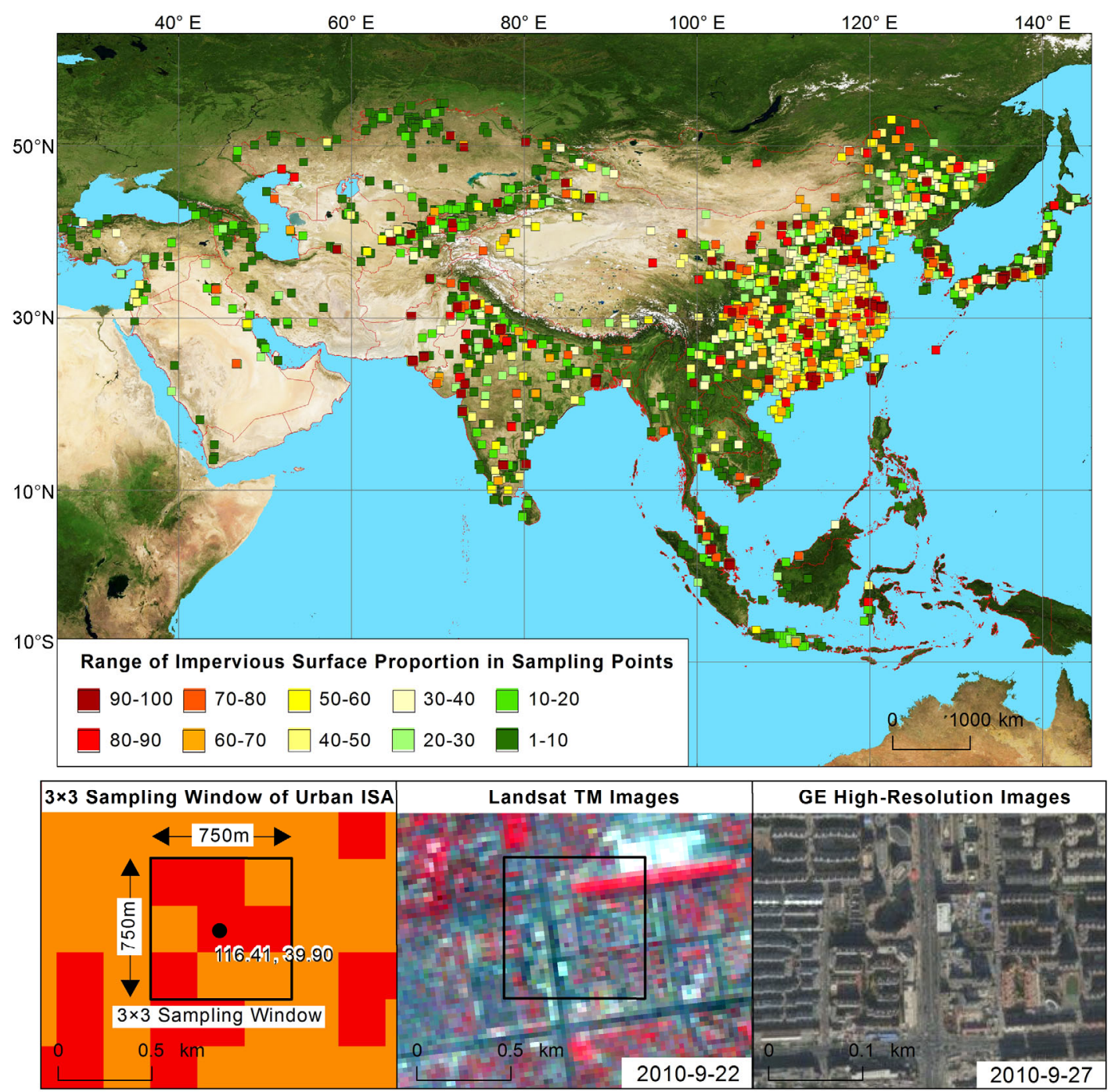

Figure 5 The distribution of sampling points and sampling scheme used to assess the classification accuracy of urban built-up areas. 


$$
\mathrm{WIS}(\beta)_{\mathrm{index}}=\left(\sum_{n=1}^{m_{\beta}} P_{\beta, n} \times A_{\beta, n}\right) / S_{\beta} \times 100 \%,
$$

where WIS $(\beta)_{\text {index }}$ represents the index of the impervious surfaces in the $\beta$ th sub-watershed; $P_{\beta, n}$ and $A_{\beta, n}$ represent the proportion of impervious surfaces and the pixel area in the $n$th grid unit and in the $\beta$ th sub-watershed, respectively; $m_{\beta}$ represents the total number of pixels of the $\beta$ th sub-watershed; and $S_{\beta}$ represents the total area of the $\beta$ th sub-watershed. Results shown that different proportions of impervious surfaces in watershed have different impacts on watershed aquatic ecosystems (Table 2).

\section{Results and analysis}

\subsection{Analysis of the classification accuracy}

Two methods were used to evaluate the accuracy of the classification results for the hierarchical structures of cities and the results are summarized in Table 3. Compared to using data from GlobeLand30, the use of fine classification and expert knowledge improved classification accuracy by $4.54 \%$. The user's and producer's accuracies of the vegetation and bare soil components are $88.56 \%$ and $87.58 \%$, respectively. The water bodies have the highest classification accuracy of over $95 \%$. Impervious surface components are dominant urban surface cover, and the values for $R^{2}$ and MRE are both 0.87 , indicating relatively high overall accu- racy of the urban built-up area and its internal components, meeting the requirements of comparative analysis of urban surface cover patterns and the detection of internal urban structures (Kuang et al., 2013, 2015c) (Table 3).

The classification results of urban surfaces show that the overall accuracy is closely related to the climate zone, the economic development level and city size of a country. The classification of urban surfaces indicates that urban impervious surfaces are mainly composed of buildings, roads and squares. The main types of vegetation and bare soils include green spaces in the parks, productive plantations and roads inside a city. Urban vegetation in the temperate and cold-temperate zones in North Asia exhibits significant seasonal characteristics, including fallen leaves, withered vegetation and bare soils in winter and spring, green vegetation in summer and autumn. In addition, relatively large differences are observed in the phenophase among regions at different latitudes. The Landsat TM and HJ-1A images were acquired at different dates, resulting in a large difference in the classification results, especially among different countries. This result is mainly attributed to two issues: (1) it is difficult to differentiate the underlying surface of a city from deserts and bare soil in arid or semiarid climate zones, which may result in an overestimation or underestimation of the density of impervious surface components; (2) high and large canopies significantly shade urban buildings in cities in tropical and subtropical zones, which may result in an underestimation of the density of impervious surface com-

Table 2 Impacts of impervious surfaces on watershed aquatic ecosystems ${ }^{\text {a) }}$

\begin{tabular}{ccc}
\hline Proportion of impervious surfaces in watershed & Impact on watershed aquatic ecosystem & None, excluded from impact features \\
\hline$<1 \%$ & Slight \\
$1-5 \%$ & Moderate \\
$5-10 \%$ & Severe \\
$10-25 \%$ & Significant \\
\hline
\end{tabular}

a) Arnold and Gibbons (1996); Bierwagen et al. (2010); Kuang (2012a); Kuang et al. (2013).

Table 3 Accuracy assessment of the urban built-up area and internal components ${ }^{\text {a) }}$

\begin{tabular}{|c|c|c|c|c|c|c|c|c|}
\hline \multirow{3}{*}{ Main countries } & \multirow{3}{*}{ Number of samples } & \multirow{3}{*}{$\begin{array}{l}\text { Overall accuracy } \\
\qquad(\%)\end{array}$} & \multicolumn{6}{|c|}{ Internal components of a city } \\
\hline & & & \multicolumn{2}{|c|}{ Urban vegetation and bare soil } & \multicolumn{2}{|c|}{ Urban water bodies } & \multicolumn{2}{|c|}{ Impervious surface components } \\
\hline & & & UA & PA & UA & PA & $R^{2}$ & MRE \\
\hline China & 1615 & 91.33 & 89.47 & 88.14 & 96.88 & 96.44 & 0.91 & 0.73 \\
\hline India & 283 & 90.11 & 88.56 & 87.17 & 95.89 & 95.38 & 0.84 & 0.95 \\
\hline Japan & 161 & 86.96 & 86.71 & 84.91 & 93.9 & 92.91 & 0.88 & 0.86 \\
\hline Kazakhstan & 126 & 90.48 & 90.18 & 88.21 & 97.65 & 96.52 & 0.89 & 0.79 \\
\hline Pakistan & 65 & 89.23 & 87.62 & 87.99 & 94.87 & 96.28 & 0.86 & 0.91 \\
\hline Uzbekistan & 51 & 88.24 & 89.03 & 88.08 & 96.41 & 96.38 & 0.85 & 0.88 \\
\hline Indonesia & 48 & 85.42 & 86.67 & 86.22 & 93.84 & 94.34 & 0.86 & 0.73 \\
\hline Other countries & 310 & 90.00 & 88.46 & 87.1 & 95.79 & 95.3 & 0.88 & 0.9 \\
\hline Total & 2725 & 90.79 & 88.56 & 87.58 & 95.89 & 95.83 & 0.87 & 0.87 \\
\hline
\end{tabular}

a) UA, user's accuracy (\%); PA, producer's accuracy $(\%) ; R^{2}$, determination of coefficient; MRE, mean relative error. 
ponents. To address these issues, we conducted a long-term typical experimental study and field measurements in cities in China, including Urumqi, Beijing, Guangzhou and Shanghai, and comparatively analyzed the 0.61-m aerial images, synthesized ortho-images and 2.1-m high-resolution Ziyuan-3 satellite images of the aforementioned cities, and identified the calibration coefficients (Kuang, 2012a, 2012c; Kuang et al., 2013, 2015c).

\subsection{Analysis of surface cover spatial distribution}

The results show that urban built-up area in Asia is $18.18 \times 10^{4} \mathrm{~km}^{2}$, accounting for $0.59 \%$ of the total land surface area of Asia (Figure 6 and Table 4). Based on the structural components within built-up areas, impervious surfaces and vegetation are the main land-cover types in cities in Asia, and water bodies and other land-cover types occupy small proportions. The total urban impervious surface is $11.65 \times 10^{4} \mathrm{~km}^{2}$, accounting for $0.38 \%$ of the total land surface area and $64.09 \%$ of the total urban built-up area in Asia. Vegetation and bare soils have an area of $6.28 \times 10^{4} \mathrm{~km}^{2}$, accounting for $34.56 \%$ of the total urban built-up area in Asia. Water bodies and other land-cover types have areas of $1872.05 \mathrm{~km}^{2}$ and $586.5 \mathrm{~km}^{2}$, respectively, accounting for $1.03 \%$ and $0.32 \%$ of the total urban built-up area in Asia, respectively.

In terms of countries' distribution in Asia, China has the largest impervious surface area $\left(3.65 \times 10^{4} \mathrm{~km}^{2}\right)$ inside the urban built-up areas, accounting for $32.77 \%$ of the total impervious surface area of Asia; followed by India and Japan with areas of $1.79 \times 10^{4} \mathrm{~km}^{2}$ and $1.33 \times 10^{4} \mathrm{~km}^{2}$, accounting for $16.10 \%$ and $11.93 \%$ respectively. Considering the economy of each country in Asia, the urbanization level in developed countries (e.g., Japan, South Korea, Singapore) and developing countries (e.g., China, India) are different. Relatively large differences are observed in the distribution and proportion of impervious surfaces among different cities. Taking the distribution intensity of impervious surfaces in the capital of each country as an example, the overall distribution range of impervious surface area in Tokyo, Seoul and Singapore City is wider than the overall distribution range in the capitals of developing countries, such as Tehran, Islamabad and Baghdad. In addition, a statistical analysis of the proportions of urban impervious surface area shows that among the developed countries, the impervious surface areas of Singapore, Japan and South Korea account for $17.12 \%, 4.88 \%$ and $3.56 \%$ of the total land area, respectively. However, among the developing countries, the impervious surface areas of China and India only account for $0.39 \%$ and $0.57 \%$ of the total land area, respectively. The significant difference in the distribution of urban impervious surfaces among countries with different development levels is closely related to the urbanization level, population scale and industrial structure of each country.

The spatial distribution of urban impervious surface in- tensity in Asia implies that the intensity and proportion of impervious surfaces in Asia exhibit a significantly decreasing trend along three gradient levels from east to west. The first gradient level covers the eastern region of Asia and includes Japan, South Korea and the coastal cities of Eastern China, which have a relatively high intensity of impervious surfaces and exhibit significantly agglomerated distribution characteristics; moreover, the impervious surface area in the coastal cities of Eastern China has the highest proportion and intensity index, and the impervious surfaces in the urban agglomerations mainly exhibit continuous distribution characteristics (Kuang et al., 2013, 2014). The second gradient level covers the central region of Asia, which typically includes the western region of Xinjiang in China, the five countries of Central Asia, India and so on, whose urban impervious surface coverage exhibits scattered distribution characteristics over a wide range, and this distribution is closely related to the scattered distribution of central cities. The third gradient level covers the western region of Asia and includes the countries in the Arabian Peninsula. The intensity index of urban impervious surfaces in the western region of Asia is insignificant, which is closely related to the climate, terrain, landform distributions and sparse population of the peninsula region.

In terms of the internal land-cover component structure within a city, the spatial structure of each surface component is affected by various factors, including natural conditions, urban planning, urban function distribution and urban development levels. The information in Figure 6 and the above analysis reveal that large differences occur in the internal land-cover structure among cities in Asian countries, and these differences are primarily due to differences in the proportions of urban impervious surfaces, vegetation, water bodies and other land-use types. Figure 7 indicates that the spatial distribution of urban impervious surface structures in Asia exhibits a basic pattern in which the proportion of urban impervious surfaces in each country is relatively large, whereas the proportions of vegetation, bare soil, water bodies and other land-use types are relatively small and are similar between different countries. The proportions of impervious surface area and vegetation in cities in Central Asian countries (e.g., India, Kazakhstan, Pakistan) are larger than those in cities in East Asian countries (e.g., Japan, China, The Philippines, Singapore), while the proportions of impervious surfaces and vegetation area in the West Asian countries in dry regions (e.g., Israel, Jordan, Turkey, Oman, Yemen) are lower than those in Central and East Asian countries. Based on a statistical analysis of the internal land-cover structural components in Asia, the land-cover structure of a city is largely affected by the economy and development level of the country. In cities with a relatively developed economy, the proportion of urban impervious surfaces is $50-60 \%$ (e.g., Korea, Singapore). Japan's and China's proportions are above $60 \%$. However, in countries with a relatively low urbanization 
Table 4 Urban land-cover structures in Asian countries ${ }^{\text {a) }}$

\begin{tabular}{|c|c|c|c|c|c|c|c|c|c|}
\hline \multirow[b]{2}{*}{ Sub-regions } & \multirow[b]{2}{*}{ Country } & \multicolumn{2}{|c|}{ Impervious surfaces } & \multicolumn{2}{|c|}{ Vegetation and bare soils } & \multicolumn{2}{|c|}{ Urban water } & \multicolumn{2}{|c|}{ Built-up area } \\
\hline & & $\begin{array}{c}\text { Area } \\
\left(\mathrm{km}^{2}\right)\end{array}$ & $\begin{array}{c}\text { Prop. } \\
(\%)\end{array}$ & $\begin{array}{c}\text { Area } \\
\left(\mathrm{km}^{2}\right) \\
\end{array}$ & $\begin{array}{c}\text { Prop. } \\
(\%)\end{array}$ & $\begin{array}{l}\text { Area } \\
\left(\mathrm{km}^{2}\right)\end{array}$ & $\begin{array}{c}\text { Prop. } \\
(\%)\end{array}$ & $\begin{array}{l}\text { Area } \\
\left(\mathrm{km}^{2}\right)\end{array}$ & $\begin{array}{r}\text { Prop. } \\
(\%)\end{array}$ \\
\hline \multirow{5}{*}{ East Asia } & China & 36525.81 & 0.39 & 20526.93 & 0.22 & 664.89 & 0.01 & 57924.97 & 0.62 \\
\hline & Japan & 13292.03 & 3.56 & 7778.68 & 2.10 & 347.24 & 0.09 & 21496.52 & 5.75 \\
\hline & South Korea & 4839.52 & 4.88 & 3261.94 & 3.33 & 52.56 & 0.05 & 8186.97 & 8.26 \\
\hline & North Korea & 460.21 & 0.38 & 418.61 & 0.35 & 9.44 & 0.01 & 892.49 & 0.73 \\
\hline & Mongolia & 315.88 & 0.02 & 69.72 & 0.00 & 4.53 & 0.00 & 390.83 & 0.02 \\
\hline \multirow{11}{*}{ Southeast Asia } & Thailand & 2992.75 & 0.58 & 3138.1 & 0.62 & 55.51 & 0.01 & 6218.06 & 1.21 \\
\hline & Malaysia & 2985.38 & 0.91 & 1972.96 & 0.60 & 24.28 & 0.01 & 5002.55 & 1.52 \\
\hline & Vietnam & 1420.36 & 0.43 & 614.78 & 0.19 & 18.42 & 0.01 & 2059.77 & 0.63 \\
\hline & Myanmar & 712.98 & 0.11 & 385.52 & 0.06 & 11.99 & 0.00 & 1114.38 & 0.17 \\
\hline & Indonesia & 5371.66 & 0.28 & 4926.61 & 0.26 & 111.15 & 0.01 & 10409.42 & 0.55 \\
\hline & The Philippines & 294.28 & 0.10 & 285.3 & 0.10 & 2.81 & 0.00 & 585.27 & 0.20 \\
\hline & Cambodia & 191.57 & 0.11 & 128.17 & 0.07 & 1.32 & 0.00 & 322.35 & 0.18 \\
\hline & Singapore & 101.67 & 17.12 & 109.76 & 18.66 & 5.65 & 0.95 & 218.19 & 36.73 \\
\hline & Laos & 48.75 & 0.02 & 38.7 & 0.02 & 1.25 & 0.00 & 89.09 & 0.04 \\
\hline & East Timor & 9.41 & 0.06 & 11.63 & 0.08 & 0.27 & 0.00 & 21.43 & 0.14 \\
\hline & Brunei & 42.69 & 0.74 & 27.12 & 0.47 & 0.66 & 0.01 & 71.28 & 1.24 \\
\hline \multirow{7}{*}{ South Asia } & India & 17946.69 & 0.57 & 3820.99 & 0.12 & 239.65 & 0.01 & 22045.93 & 0.70 \\
\hline & Pakistan & 4880.12 & 0.01 & 961.27 & 0.01 & 18.08 & 0.00 & 5869.18 & 0.02 \\
\hline & Bangladesh & 522.10 & 0.38 & 148.94 & 0.11 & 7.58 & 0.01 & 680.12 & 0.50 \\
\hline & Sri Lanka & 438.21 & 0.66 & 127.92 & 0.19 & 3.5 & 0.01 & 570.92 & 0.86 \\
\hline & Nepal & 54.36 & 0.04 & 16.32 & 0.01 & 1.17 & 0.00 & 72.01 & 0.05 \\
\hline & Bhutan & 42.15 & 0.09 & 23.71 & 0.05 & 0.71 & 0.00 & 66.91 & 0.15 \\
\hline & Maldives & 0.69 & 0.23 & 0.32 & 0.11 & 0.02 & 0.01 & 1.04 & 0.35 \\
\hline \multirow{5}{*}{ Central Asia } & Kazakhstan & 8069.48 & 0.30 & 2021.67 & 0.08 & 43.11 & 0.00 & 10154.68 & 0.38 \\
\hline & Uzbekistan & 3539.20 & 0.82 & 1528.01 & 0.36 & 48.19 & 0.01 & 5130.83 & 1.18 \\
\hline & Turkmenistan & 1599.15 & 0.33 & 1473.6 & 0.30 & 17.05 & 0.00 & 3104.68 & 0.63 \\
\hline & Kyrgyzstan & 1082.24 & 0.54 & 779.12 & 0.39 & 16.01 & 0.01 & 1885.24 & 0.95 \\
\hline & Tajikistan & 587.09 & 0.41 & 505.07 & 0.36 & 12.39 & 0.01 & 1109.65 & 0.78 \\
\hline \multirow{20}{*}{ West Asia } & Iran & 1692.82 & 0.10 & 1890.32 & 0.12 & 24.02 & 0.00 & 3626.25 & 0.22 \\
\hline & Turkey & 1108.09 & 0.14 & 1072.13 & 0.14 & 24.95 & 0.00 & 2216 & 0.28 \\
\hline & Saudi Arabia & 793.07 & 0.04 & 736.55 & 0.04 & 13.49 & 0.00 & 1550.55 & 0.08 \\
\hline & Iraq & 782.13 & 0.18 & 749.64 & 0.17 & 14.23 & 0.00 & 1553.57 & 0.36 \\
\hline & Georgia & 631.55 & 0.90 & 565.52 & 0.82 & 11.58 & 0.02 & 1214.36 & 1.74 \\
\hline & Azerbaijan & 579.58 & 0.67 & 546.29 & 0.64 & 10.26 & 0.01 & 1141.65 & 1.32 \\
\hline & Israel & 450.26 & 2.05 & 515.64 & 2.37 & 10.76 & 0.05 & 981.87 & 4.47 \\
\hline & Armenia & 418.95 & 1.41 & 392.76 & 1.34 & 10.25 & 0.03 & 825.93 & 2.78 \\
\hline & Afghanistan & 415.35 & 0.06 & 140.58 & 0.02 & 6.63 & 0.00 & 563.98 & 0.09 \\
\hline & Syria & 278.67 & 0.15 & 201.86 & 0.11 & 3.81 & 0.00 & 486.38 & 0.26 \\
\hline & Kuwait & 258.08 & 1.49 & 247.15 & 1.44 & 5.1 & 0.03 & 512.83 & 2.96 \\
\hline & $\begin{array}{l}\text { United Arab Emir- } \\
\text { ates }\end{array}$ & 180.65 & 0.26 & 96.89 & 0.14 & 3.71 & 0.01 & 282.23 & 0.40 \\
\hline & Jordan & 119.62 & 0.13 & 138.48 & 0.16 & 2.52 & 0.00 & 262.02 & 0.29 \\
\hline & Lebanon & 99.91 & 0.99 & 91.58 & 0.91 & 2.41 & 0.02 & 194.83 & 1.92 \\
\hline & Qatar & 78.65 & 0.69 & 87.88 & 0.78 & 2.13 & 0.02 & 169.55 & 1.49 \\
\hline & Cyprus & 73.61 & 0.82 & 79.07 & 0.89 & 2.41 & 0.03 & 155.89 & 1.73 \\
\hline & Yemen & 56.56 & 0.01 & 81.69 & 0.02 & 1.66 & 0.00 & 140.74 & 0.03 \\
\hline & Bahrain & 32.91 & 4.89 & 28.24 & 4.24 & 0.76 & 0.11 & 62.2 & 9.24 \\
\hline & Oman & 21.43 & 0.01 & 28.74 & 0.01 & 0.8 & 0.00 & 51.26 & 0.02 \\
\hline & Pakistan & 66.40 & 0.56 & 30.91 & 0.11 & 1.14 & 0.00 & 99.11 & 0.67 \\
\hline \multicolumn{2}{|c|}{ Total } & $11.65 \times 10^{4}$ & 0.38 & $6.28 \times 10^{4}$ & 0.18 & 1872.05 & 0.01 & $18.18 \times 10^{4}$ & 0.59 \\
\hline
\end{tabular}

a) Prop., proportion of country lands in the world. 

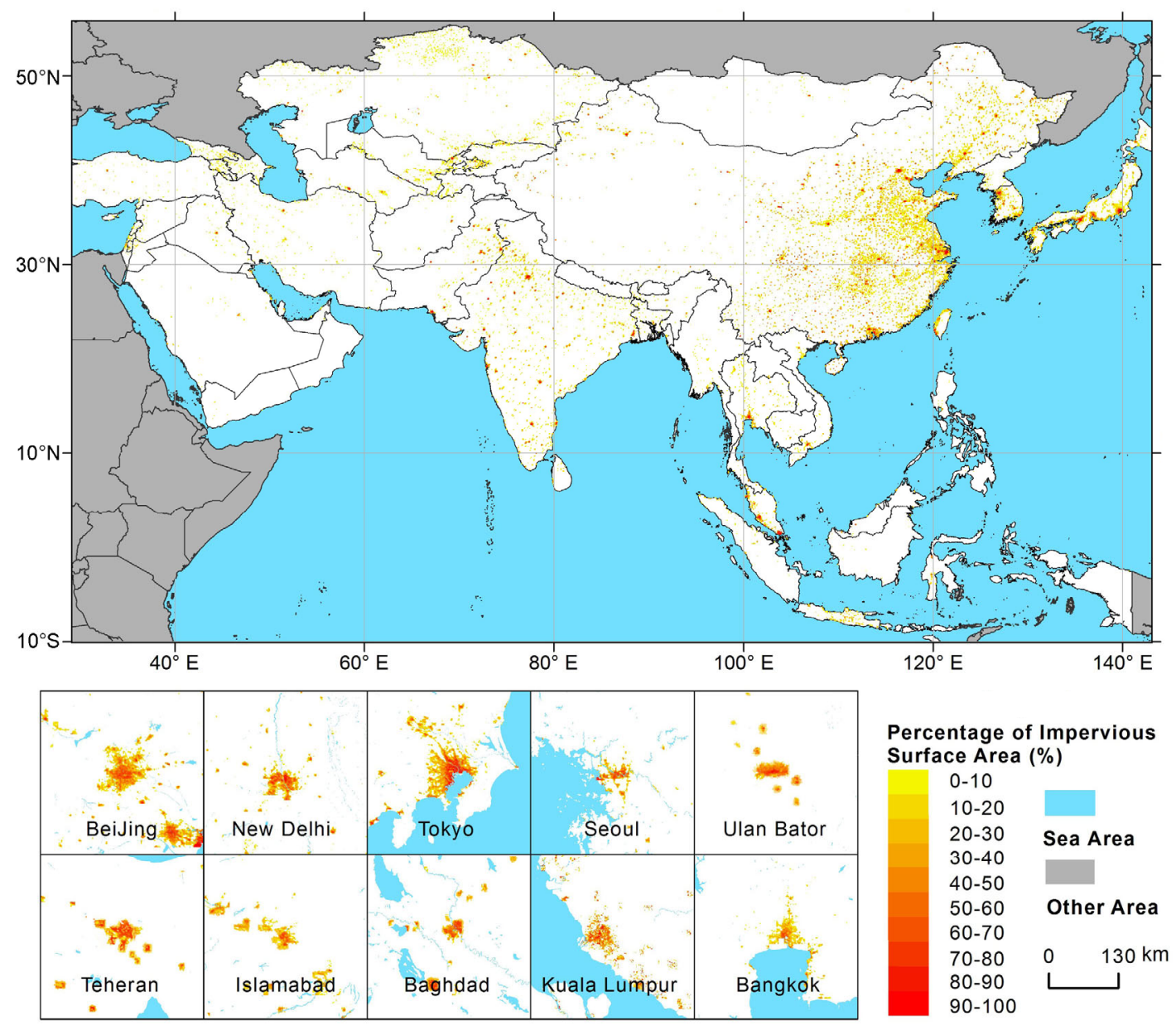

Figure 6 Spatial distribution and area ratio of artificial surface cover in Asia.

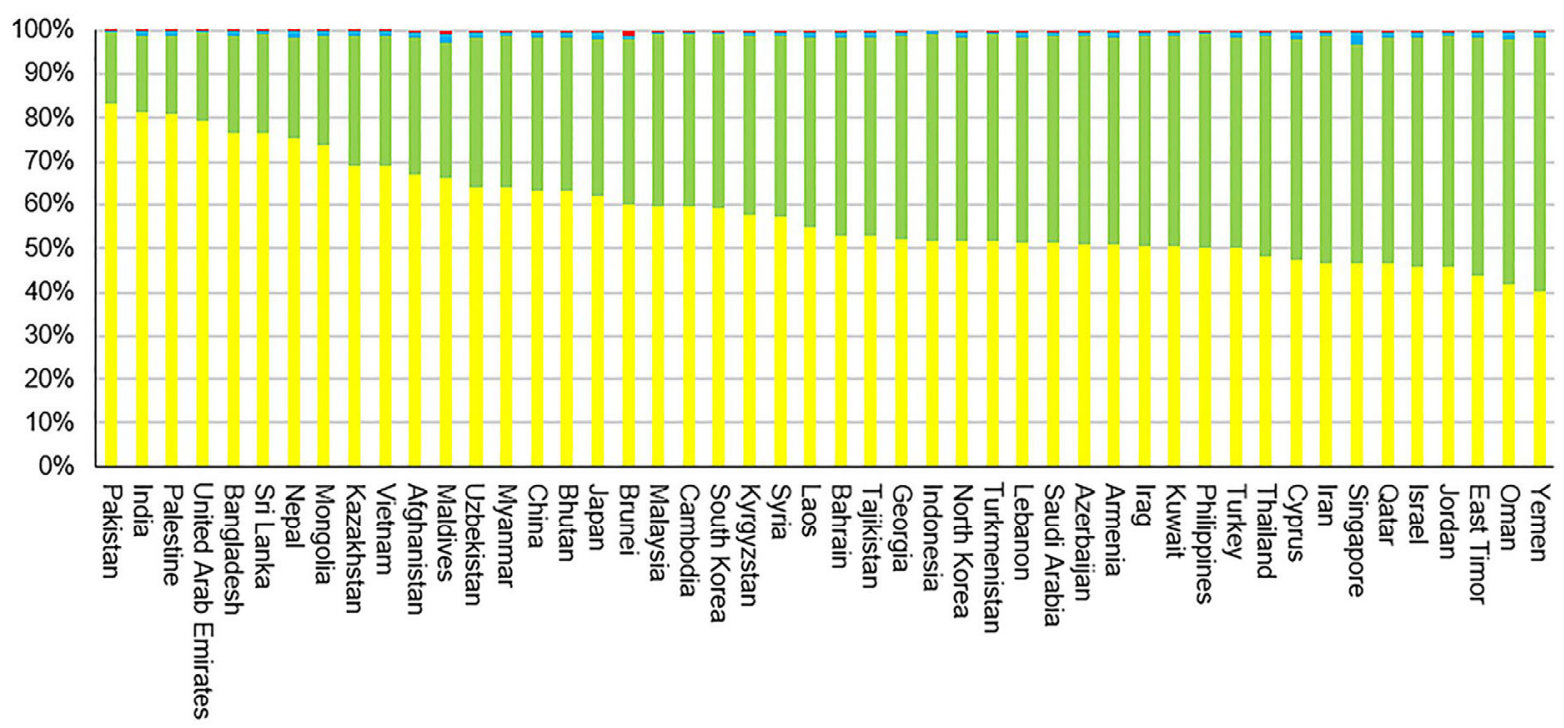

Percentage of Urban ISA

- Percentage of Urban Water Body

\section{a Percentage of Urban Green Space}

- Percentage of Urban Other Land Cover

Figure 7 Percentages of urban land cover components in Asian countries. 
rate and a relatively low level of development, such as India and Pakistan, the proportion of urban impervious surfaces is close to or exceeds $80 \%$, whereas the proportion of vegetation is relatively small.

\subsection{Spatial distribution characteristics of the propor-} tions of urban impervious surfaces in sub-watersheds in Asia

There are 7788 sub-watersheds in Asia. A spatial overlay analysis of urban impervious surfaces and sub-watersheds in Asia was conducted to obtain the proportion of urban impervious surface area in different sub-watersheds (Figure $8)$. In 2010, the sub-watersheds in Asia had a total area of $2709.08 \times 10^{4} \mathrm{~km}^{2}$, accounting for $88.19 \%$ of the total land surface area of Asia, and the proportion of urban impervious surface area in these watersheds was less than $1 \%$. Sub-watershed areas with a proportion of urban impervious surface area between $1 \%$ and $5 \%$ account for $9.17 \%$ of the total land surface area of Asia, and sub-watershed areas with a proportion of urban impervious surface area between $5 \%$ and $25 \%$ account for $2.29 \%$ of the total land surface area of Asia. In terms of spatial distribution, sub-watersheds with a proportion of urban impervious surface area greater than $25 \%$ have an area of $10.62 \times 10^{4} \mathrm{~km}^{2}$, accounting for $0.35 \%$ of the total land surface area of Asia. These subwatersheds are centrally distributed in East Asian countries, such as Japan, South Korea and China (particularly the coastal areas of Eastern China). Among them, urban impervious surfaces are distributed at high proportions in the Beijing-Tianjin-Hebei region, the Yangtze River Delta region, the Pearl River Delta region, the coastal region of western Taiwan and the Pacific coastal region in Japan.
Based on the statistical analysis of the areas and proportions of urban impervious surfaces in the watersheds of Asia (Table 5), at $1-5 \%$, China has the largest urban impervious surface area $\left(127.62 \times 10^{4} \mathrm{~km}^{2}\right)$, followed by India, Kazakhstan and Japan. Between 5\% and 25\%, China has the largest area, followed by Japan and India. At greater than $25 \%$, China has the largest area, followed by Japan (Table 5).

In terms of the characteristics of watersheds in China, the impact of urban impervious surfaces on areas in the upstream of the major watersheds is limited to nonexistent. For example, only a small number of sub-watersheds are slightly affected by urban impervious surfaces; they are sporadically distributed in the upstream of certain watersheds, including Yangtze, Yellow, Pearl and Songhuajiang watersheds. In contrast, urban impervious surfaces have a slight or significant impact on ecosystems in the downstreams of the major watersheds. The Songhuajiang and Liaohe watersheds are the main watersheds of northeast China, and the sub-watersheds that are slightly affected by urban impervious surfaces are widely distributed; in addition, the urban built-up areas of Harbin and Shenyang are moderately or severely affected by urban impervious surfaces. The Yellow, Haihe and Huaihe watersheds are the main watersheds of central China. The sub-watersheds that are slightly affected by urban impervious surfaces are distributed over a wide range and cover the majority of central China, with moderately or severely affected watersheds in Shandong and Henan, and significantly affected in the Beijing-Tianjin-Hebei region and the southern Shandong Peninsula. The Yangtze River watershed is the main watershed in the region of the lower reaches of the Yangtze River (i.e., Zhejiang, Jiangsu, Shanghai), and the sub-watersheds distributed throughout Shanghai metropolitan region are sig-

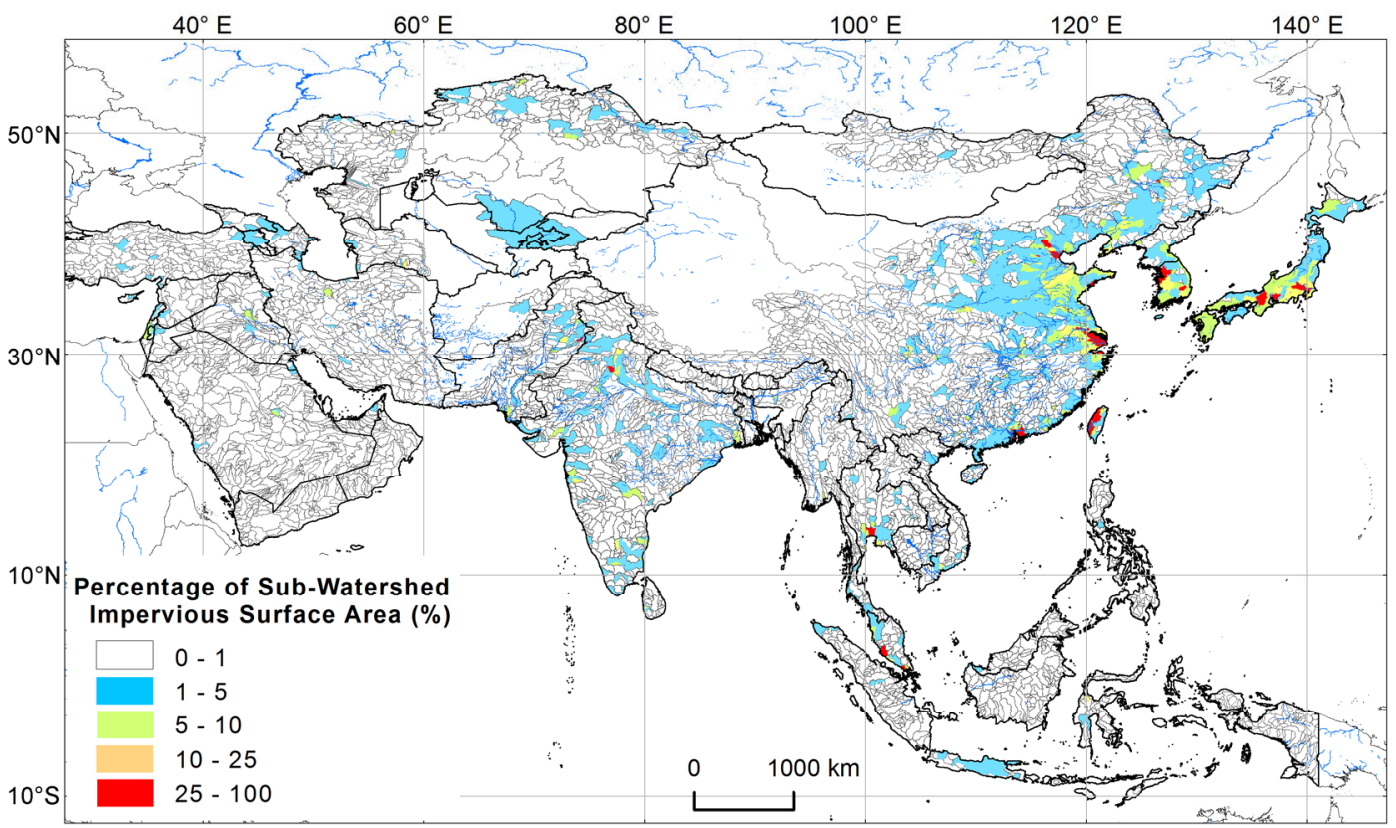

Figure 8 Spatial distribution map of sub-watersheds in Asia with different levels of urban impervious surfaces. 
nificantly affected by urban impervious surfaces; in addition, a large number of slightly, moderately or severely affected areas are located at the junction of Jiangsu, Zhejiang and Anhui. The Pearl River watershed is the main watershed of the Pearl River Delta region, and the sub-watersheds are distributed throughout Guangdong, Zhuhai, Hong Kong and Macau. They are significantly affected by urban impervious surfaces, whereas other sub-watersheds are only slightly affected by urban impervious surfaces (Table 6 and Figure 8).

Table 5 Sub-watershed areas with different proportions of urban impervious surfaces in Asia ${ }^{\text {a) }}$

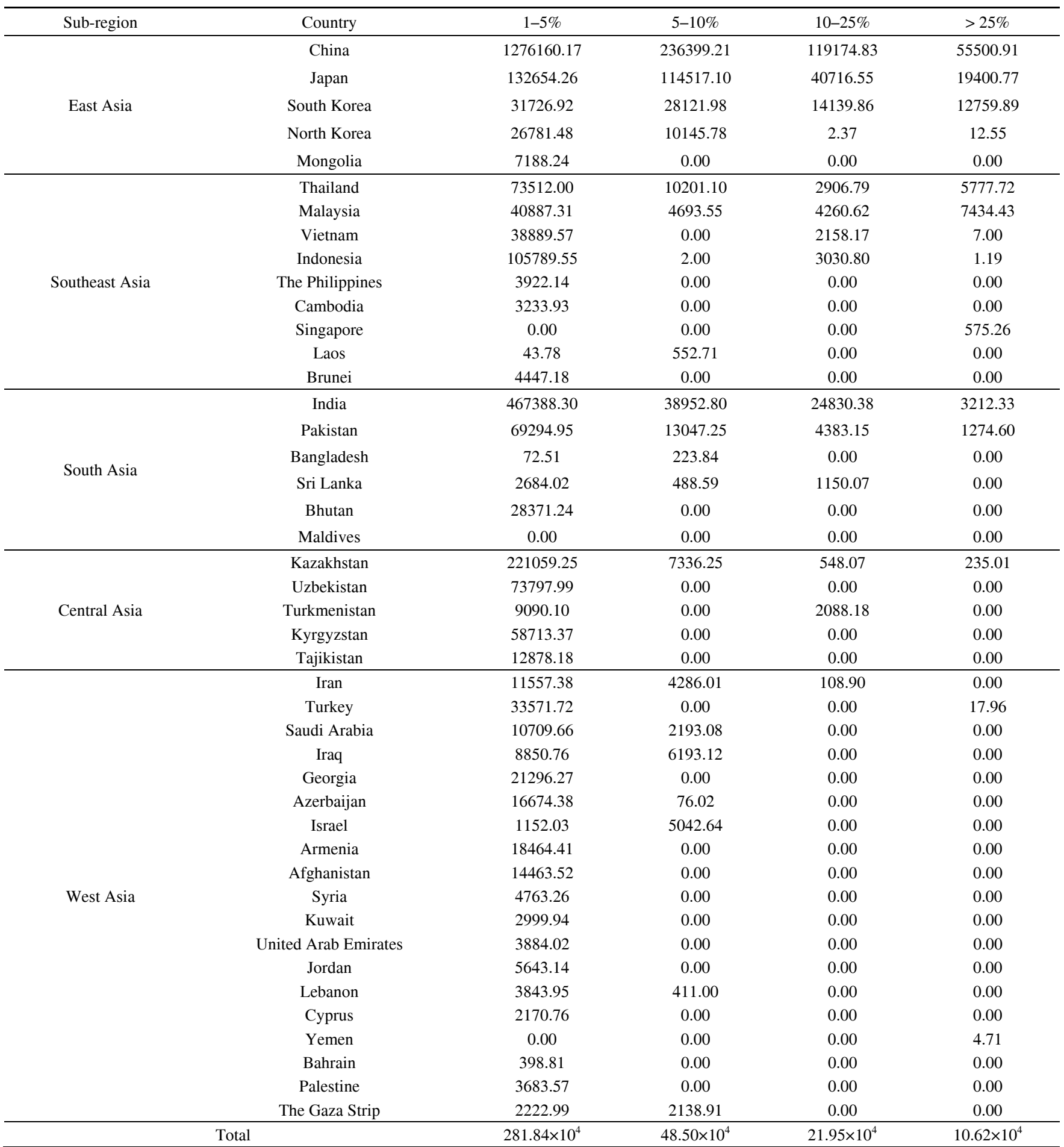

a) The percentages (e.g., 1-5\%) represent the areas of sub-watersheds in which the impervious surface area accounts for the total area of the subwatershed $\left(\mathrm{km}^{2}\right)$. 
Table 6 Proportions of impervious surfaces distributed in major watersheds in China ${ }^{\text {a) }}$

\begin{tabular}{|c|c|c|c|c|}
\hline Watershed & $1-5 \%$ & $5-10 \%$ & $10-25 \%$ & $>25 \%$ \\
\hline Hai River & 5557.36 & 2377.14 & 835.21 & 4433.04 \\
\hline Huai River & 5469.41 & 4496.33 & 4563.44 & 939.53 \\
\hline Yellow River & 5412.63 & 1292.57 & 727.07 & 323.14 \\
\hline Yangtze River & 4060.44 & 3137.61 & 4429.57 & 8120.88 \\
\hline Pearl River & 2056.09 & 881.18 & 1351.14 & 5052.11 \\
\hline Songhua River & 3435.03 & 1175.14 & 361.58 & 361.58 \\
\hline
\end{tabular}

a) The percentages (e.g., 1-5\%) represent the areas of sub-watersheds in which the impervious surface area accounts for the total area of the sub-watershed $\left(\mathrm{km}^{2}\right)$.

Based on the aforementioned analysis, the spatial distribution of areas impacted by impervious surfaces can be determined within the seven major river watersheds of China. The proportion of areas with slightly affected sub-watersheds gradually decreases from north to south, whereas the proportion of areas with significantly affected sub-watersheds gradually increases; thus, the impact of impervious surfaces on each watershed gradually increases from north to south. The impacts of impervious surfaces on the sub-watersheds in each of the seven major rivers in China were analyzed from north to south. Table 6 indicates that the Songhuajiang River watershed is slightly or moderately affected with areas of 3435.03 and $1175.14 \mathrm{~km}^{2}$, respectively by urban impervious surfaces. The sub-watershed area of Liaohe River that is slightly affected by urban impervious surfaces is equivalent to that of significantly affected area, approximately $2000 \mathrm{~km}^{2}$. The slightly affected sub-watersheds of Haihe River have the largest area $\left(5557.36 \mathrm{~km}^{2}\right)$ of all the slightly affected sub-watersheds, and the significantly affected sub-watersheds cover 4433.04 $\mathrm{km}^{2}$. Most of the Yellow River sub-watersheds are slightly affected by urban impervious surfaces and have an area of approximately $5412.63 \mathrm{~km}^{2}$. The slightly, moderately and severely affected Huaihe River sub-watersheds are all large areas, whereas the significantly affected sub-watersheds are small areas. The significantly affected Yangtze River sub-watersheds have the largest area (circa $8120.88 \mathrm{~km}^{2}$ ), whereas the sub-watersheds affected to other degrees have relatively small areas but cannot be neglected. The Pearl River sub-watersheds are significantly affected (circa $5052.11 \mathrm{~km}^{2}$ ), but mostly are slightly affected.

\section{Discussion}

\subsection{Detection of the internal structural components of a city}

Urban landscapes are highly dynamic and structurally complicated, and they include different mosaics. The internal impervious surfaces and green-space structural components of a city have different impacts on the ecosystems of a city and may alter the urban heat island effect. Current research on urban land-use and land-cover changes does not include descriptions of the internal heterogeneity and structural components of the urban expansion process, which limits the reliability of urban surface heat budget simulations and ecosystem services evaluations (Kuang et al., 2015a, 2015b). Most product resolution of urban built-up areas or impervious surfaces data at global or intercontinental scale is 500-m or 1-km (Yang et al., 2003; Schneider et al., 2009). Through a comparative analysis of similar datasets developed by other researchers with our recent results, we found that the differences in the classification system, spatial resolution and data acquisition time lead to data products with different qualities and quantities (Liu J Y et al., 2014). An analysis of the related literature points out that different definitions of urban concepts and insufficient understandings on the mixture of impervious surfaces and green spaces within a city are main factors causing the differences among the remote sensing monitoring results (Kuang et al., 2014; Lu et al., 2014b).

Elvidge et al. (2007) estimated the global impervious surface area using the DMSP, but the impervious surface area was overestimated because of insufficient descriptions of the internal heterogeneity of cities in the $1-\mathrm{km}$ resolution images. Wu and David (2002) and Liu Z F et al. (2014) proposed a three-level urban land classification system in which urban land was classified into urban area, urban built-up area and impervious surfaces. They evaluated a large amount of past research and concluded that the urban impervious surface area of Asia accounts for $0.60 \%$ of the total land area of Asia and that the ratio of urban impervious surface areas in urban built-up areas in Asia was 1:1.5 (Wu and David, 2002; Liu Z F et al., 2014). Based on our evaluation, the urban built-up area in Asia was $18.18 \times 10^{4} \mathrm{~km}^{2}$, accounting for $0.59 \%$ of the total land surface area of Asia in 2010. Among the internal cover components of cities, impervious surfaces have a total area of $11.65 \times 10^{4} \mathrm{~km}^{2}$, accounting for $64.09 \%$ of the total urban built-up area in Asia, whereas the vegetation and bare soil area accounts for $34.56 \%$. Thus, our evaluation results are closer to the evaluation results reported by Liu Z F et al. (2014).

\subsection{Intensity and influencing factors of urban devel- opment and construction in Asia}

The intensity and proportions of impervious surface in Asia 
exhibit a significantly decreasing trend over three gradient levels. This trend is mainly determined by the overall terrain, landforms and natural environment of Asia, the historical development stage of each country and the coastal nature of the export-oriented economies. The spatial distribution reflects the current developmental intensity of urban construction in Asia. Overall, the first gradient centers on the countries in East Asia, including China, Japan and South Korea. Cities in these countries are distributed in clusters, and the impervious surfaces of the urban agglomerations (e.g., the Beijing-Tianjin-Tangshan agglomeration, the Pearl River Delta agglomeration, the Yangtze River Delta agglomeration and the Pacific coastal agglomerations in Japan) exhibit continuous distribution characteristics; moreover, this gradient is closely related to the export-oriented economies of the coastal cities. The second gradient covers the central region of Asia, which includes countries in Central Asia, Southeast Asia and South Asia. India has the largest urban impervious surface distribution in this region, and the gradient is more significantly related to the historical development level of each country. The third gradient centers on the countries in West Asia, which has a small population density and is more significantly restrained by the natural and geographical environment. According to historical views and current population distributions, China and India are among the four great ancient civilizations and have large populations. Moreover, China and India are ranked as the top two in terms of urban built-up areas in Asia, and they play significant roles in the Asian urbanization process.

The development of urban construction within each country is closely related to urban population and economic development. The multiple correlation coefficients $\left(R^{2}\right)$ of 0.80 and 0.87 between urban impervious surface area/urban population and /economy, respectively, confirmed the close relationships (Figure 9). The urban impervious surface area is linearly related to the urban population and the gross do- mestic product (GDP). The urban built-up areas and internal impervious surface component proportions indicate a significant difference between developed and developing countries. Developing countries increase the urbanization rate mainly by increasing the urban impervious surface area, and the ecological service function of urban green vegetation is not generally considered. However, developed countries place more emphasis on the internal greening of cities and the construction of residential environments. Therefore, developed countries have a smaller proportion of urban internal impervious surface components compared to developing countries. Such results are consistent with the patterns obtained from a comparison between the extremely large cities of China and the USA (Kuang et al., 2014).

\subsection{Impacts of urbanization on the sub-watershed en- vironment in Asia}

Asia is undergoing a rapid urbanization process, and the urban population in Asia accounted for $43 \%$ of the global population in 2010. Overall, Japan and South Korea experienced rapid urbanization in the 1980s, and emerging countries, such as China, India and Bangladesh, have also experienced rapid development. The accelerating urbanization in Asia has impacted the eco-environments of the watersheds. Based on our evaluation, sub-watersheds with a proportion of urban impervious surface area greater than $25 \%$ have an area of $10.62 \times 10^{4} \mathrm{~km}^{2}$. China has the largest area of watersheds with a proportion of urban impervious surface area greater than $25 \%\left(5.55 \times 10^{4} \mathrm{~km}^{2}\right)$, followed by Japan. Those watersheds are centrally distributed in China and within the urban agglomeration regions on the east coast of Japan (Kuang, 2012a; Kuang et al., 2013). Because urban and industrial development in most countries in Asia has been based on resource consumption and traditional manufacturing industries, the high-density distribution of urban impervious surfaces has caused a series of eco-
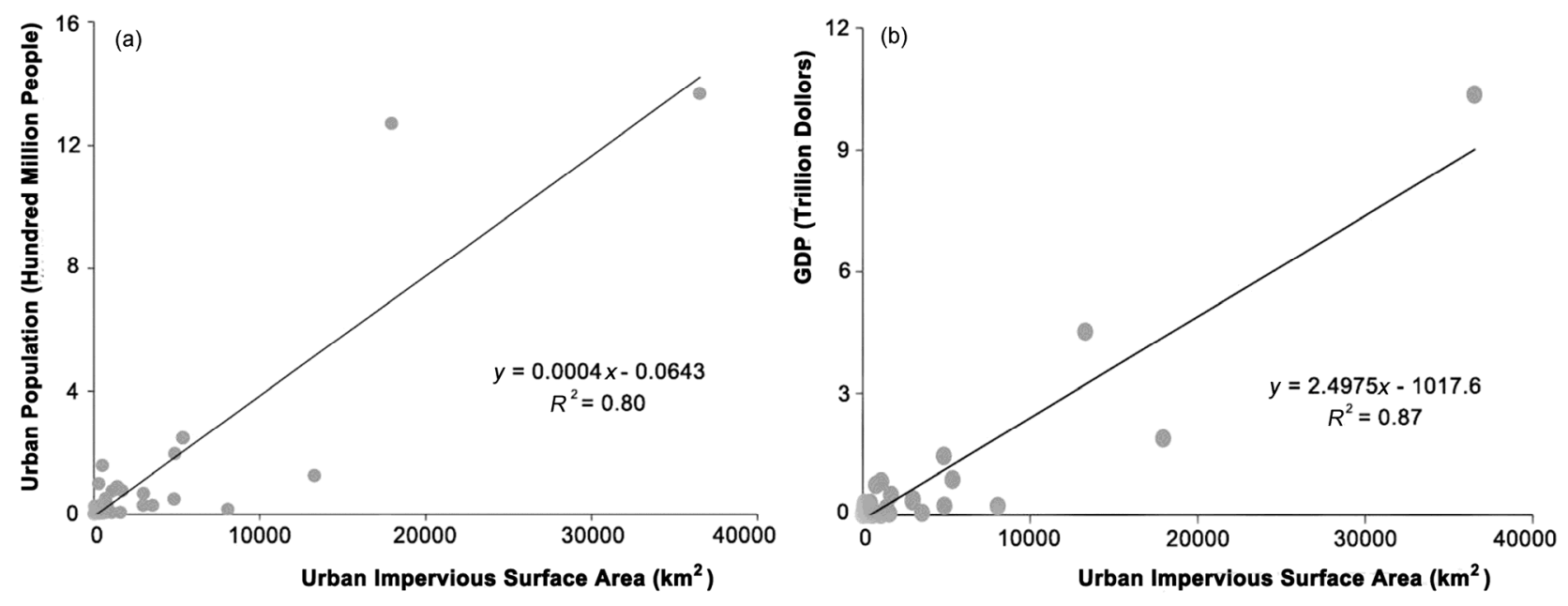

Figure 9 Fitting curves for urban impervious surface area vs urban population and urban impervious surface area vs GDP. 
environmental problems. Thus, urbanization in Asia is facing the improvements of living environments, environmental pollution, infrastructure and other issues, which will be great challenges for the achievement of sustainable urban development (Wu, 2013; Kuang et al., 2015c).

\section{Conclusions}

This study constructed a hierarchical-structure classification system for artificial surface, urban built-up area, impervious surface and vegetation cover components, developed a new approach to extract the pixel components of subclass artificial surface cover based on GlobeLand30, and produced products of proportional urban built-up areas, impervious surface and vegetation cover components in Asia in 2010 with 250-m resolution. The classification of urban built-up areas in Asia in 2010 was based on multisource data integration and expert knowledge, and had an overall accuracy of $91 \%$. The extraction of the impervious surface component had an MRE of 0.87 . The proposed method can be used in detection and estimation of the internal structure of a city. There were $18.18 \times 10^{4} \mathrm{~km}^{2}$ of urban built-up area in Asia, accounting for $0.59 \%$ of the total land surface area of Asia. Among the internal cover components of cities, impervious surfaces had a total area of $11.65 \times 10^{4} \mathrm{~km}^{2}$ accounting for $64.09 \%$ of the total urban area of Asia, whereas vegetation and bare soil accounted for $34.56 \%$ of the total urban built-up area in Asia. This spatial pattern reflects the impacts on the watershed ecosystems caused by human activities such as urban construction.

The intensity and proportions of urban impervious surfaces in Asia exhibit a three-level (continuous, scattered in central cities and indeterminate) gradient distribution pattern from east to west. Among the countries in Asia, China has the largest urban impervious surface areas, followed by India and Japan. Overall, developed countries have a larger proportion of urban impervious surface area compared to developing countries. However, in terms of the internal structures of cities, the proportion of impervious surface areas inside the urban built-up areas in countries with relatively developed economies is smaller than in countries with a relatively low level of development.

The sub-watershed area in Asia with a proportion of urban impervious surface area greater than $25 \%$ accounts for $0.35 \%$ of the total land surface area of Asia; such subwatersheds are mainly distributed in East Asian countries, such as Japan, South Korea and China (particularly the coastal regions of Eastern China). The ecosystems of the downstreams of the major watersheds, to some extent, have been affected by urban impervious surfaces. Differences in the urbanization, industrialization and economic development levels among countries in Asia cause significant differences in urban built-up areas as well as component structures of impervious surface and green space inside urban built-up areas.
Acknowledgements We appreciated the two anonymous reviewers, constructive comments and suggestions. This work was financially supported by the National Natural Science Foundation of China (Grant Nos. 41371408 \& 41371409), the National High Technology Research and Development Program of China (Grant No. 2013AA122802), and the State Key Development Program for Basic Research of China (Grant No. 413714082014CB954302).

\section{References}

Arnold C L, Gibbons C J. 1996. Impervious surface coverage: The emergence of a key environmental indicator. J Am Plann Assoc, 62: 243-258

Bierwagen B G, Theobald D M, Pyke C R, Choate A, Groth P, Thomas J V, Morefield P. 2010. National housing and impervious surface scenarios for integrated climate impact assessments. Proc Natl Acad Sci USA, 10: 20887-20892

Boysen L R, Brovkin V, Arora V K, Cadule P, Noblet-Ducoudré N, Kato E, Pongratz J, Gayler V. 2014. Global and regional effects of land-use change on climate in 21 st century simulations with interactive carbon cycle. Earth Syst Dynam, 5: 309-319

Cao X, Chen J, Chen L J, Liao A P, Sun F D, Li Y, Li L, Lin Z H, Pang Z G, Chen J, He C Y, Peng S. 2014. Preliminary analysis of the spatial pattern and fluctuations of global land surface water. Sci China Earth Sci, 44: 1661-1670

Chen J, Ban Y F, Li S N. 2014a. China: Open access to Earth land-cover map. Nature, 514: 434

Chen J, Chen J, Liao A P, Cao X, Chen L J, Chen X H, Peng S, Han G, Zhang H W, He C Y, Wu H, Lu M. 2014b. Concepts and key techniques for $30 \mathrm{~m}$ global land cover mapping (in Chinese). Acta Geodaetica Cartograph Sin, 43: 551-557

Chen J, Chen J, Liao A P, Cao X, Chen L J, Chen X H, He C Y, Han G, Peng S, Lu M, Zhang W W, Tong X H, Mills J. 2015. Global land cover mapping at $30 \mathrm{~m}$ resolution: A POK-based operational approach. ISPRS J-Photogramm Remote Sens, 103: 7-27

Elvidge C D, Tuttle B T, Sutton P C, Baugh K E, Howard A T, Milesi C, Bhaduri B L, Nemani R. 2007. Global distribution and density of constructed impervious surfaces. Sensors, 7: 1962-1979

Grimm N B, Faeth S H, Golubiewski N E, Redman C L, Wu J G, Bai X M, Briggs J M. 2008. Global change and the ecology of cities. Science, 319: 756-760

Grimmond S. 2007. Urbanization and global environmental change: Local effects of urban warming. Geogr J, 173: 83-88

Hodgson M E, Jensen J R, Schmidt L, Schill S, Davis B. 2003. An evaluation of LIDAR- and IFSAR-derived digital elevation models in leaf-on conditions with USGS Level 1 and Level 2 DEMs. Remote Sens Environ, 84: 295-308

Hu X F, Weng Q H. 2009. Estimating impervious surfaces from medium spatial resolution imagery using the self-organizing map and multi-layer perceptron neural networks. Remote Sens Environ, 113: 2089-2102

Kuang W H. 2012a. Evaluating impervious surface growth and its impacts on water environment in Beijing-Tianjin-Tangshan metropolitan area. J Geogr Sci, 22: 535-547

Kuang W H. 2012b. Spatio-temporal patterns of intra-urban land use change in Beijing, China between 1984 and 2008. J Geogr Sci, 22: 210-220

Kuang W H. 2012c. Digital Reconstruction, Analysis and Simulation of the Spatio-Temporal Information of Urban Land Use (in Chinese). Beijing: Science Press

Kuang W H, Liu J Y, Zhang Z X, Lu D S, Xiang B. 2013. Spatiotemporal dynamics of impervious surface areas across China during the early 21st century. Chin Sci Bull, 58: 1691-17011

Kuang W H, Chi W F, Lu D S, Dou Y Y. 2014. A comparative analysis of megacity expansions in China and the US: Patterns, rates and driving forces. Landscape Urban Plan, 132: 121-135 
Kuang W H, Liu Y, Dou Y Y, Chi W F, Chen G S, Gao C F, Yang T R, Liu J Y, Zhang R H. 2015a. What are hot and what are not in an urban landscape: Quantifying and explaining the land surface temperature pattern in Beijing, China. Landsc Ecol, 30: 357-373

Kuang W H, Dou Y Y, Zhang C, Chi W F, Liu A L, Zhang R H, Liu J Y. 2015b. Quantifying the heat flux regulation of metropolitan land-use/land-cover components by coupling remote sensing-modelling with in situ measurement. J Geophys Res-Atmos, 120: 113-130

Kuang W H, Chi W F, Lu D S. 2015c. Remote Sensing Analysis and Ecological Regulation of the Thermal Environment of Urban Surfaces (in Chinese). Beijing: Science Press

Liao A P, Chen L J, Chen J, He C Y, Cao X, Chen J, Peng S, Sun F D, Gong P. 2014. High-resolution remote sensing mapping of global land surface water. Sci China Earth Sci, 44: 1634-1645

Liu J Y, Zhang Z X, Xu X L, Kuang W H, Zhou W C, Zhang S W, Li R D, Yan C Z, Yu D S, Wu S X, Jiang N. 2010. Spatial patterns and driving forces of land use change in China during the early 21 st century. $\mathrm{J}$ Geogr Sci, 20: 483-494

Liu J Y, Kuang W H, Zhang Z X, Xu X L, Qin Y W, Ning J, Zhou W C, Zhang S W, Li R D, Yan C Z, Wu S X, Shi X Z, Jiang N, Yu D S, Pan X Z, Chi W F. 2014. Spatiotemporal characteristics, patterns, and causes of land-use changes in China since the late 1980s. J Geogr Sci, 24: 195-21

Liu Z F, He C Y, Zhou Y Y, Wu J G. 2014. How much of the world's land has been urbanized, really? A hierarchical framework for avoiding confusion. Landsc Ecol, 29: 763-771

Lu D D. 2014. The framework document of "Future Earth" and the development of Chinese geographical science: The foresight of Academician HUANG Bingwei's statement (in Chinese). Acta Geogr Sin, 69: 1043-1051

Lu D S, Weng Q H. 2004. Spectral mixture analysis of the urban landscapes in Indianapolis with Landsat ETM+ imagery. Photogramm Eng Rem Sens, 70: 1053-1062

Lu D S, Tian H Q, Zhou G M, Ge H L. 2008. Regional mapping of human settlements in southeastern China with multisensory remotely sensed data. Remote Sens Environ, 112: 3668-3679

Lu D S, Li G Y, Moran E. 2014a. Current situation and needs of change detection techniques. Int J Image Data Fusion, 5: 13-38

Lu D S, Li G Y, Kuang W H, Moran E. 2014b. Methods to extract impervious surface areas from satellite images. Int J Digit Earth, 7: 93-112

Messerli B, Grosjean M, Hofer T, Núñez L, Pfister C. 2000. From nature-dominated to human-dominated environmental changes. IGU Bull, 50: 23-38

Nowak D J, Greenfield E J. 2012. Tree and impervious cover in the United States. Landscape Urban Plan, 107: 21-30

Schneider A, Friedl M A, Potere D. 2009. A new map of global urban extent from MODIS satellite data. Environ Chem Lett, 4: 940-941

Slonecker E T, Jennings D B, Garofalo D. 2001. Remote sensing of impervious surface: A review. Remote Sens Rev, 20: 227-255

Sterling S M, Ducharne A, Polcher J. 2013. The impact of global land-cover change on the terrestrial water cycle. Nat Clim Change, 3: 385-390

Wu J G, David J L. 2002. A spatially explicit hierarchical approach to modeling complex ecological systems: Theory and applications. Ecol Model, 153: 7-26

Wu J G. 2013. Landscape sustainability science: Ecosystem services and human well-being in changing landscape. Landsc Ecol, 28: 999-1023

Xian G, Crane M. 2005. Assessments of urban growth in the Tampa Bay watershed using remote sensing data. Remote Sens Environ, 97: 203-215

Xian G, Homer C. 2010. Updating the 2001 national land cover database impervious surface products to 2006 using Landsat imagery change detection methods. Remote Sens Environ, 114: 1676-1686

Yan Y, Kuang W H, Zhang C, Chen C B. 2015. Impacts of impervious surface expansion on soil organic carbon: A spatially explicit study. Sci Rep, 5: 17905, doi: 10.1038/srep17905

Yan Y, Zhang C, Hu Y F, Kuang W H. 2016. Urban land-cover change and its impact on the ecosystem carbon storage in a dryland city. Remote Sens, 8: 6, doi: 10.3390/rs801000

Yang L, Huang C Q, Homer C G, Wylie B K, Coan M J. 2003. An approach for mapping large-area impervious surfaces: Synergistic use of landsat-7 ETM+ and high spatial resolution imagery. Can J Remote Sens, 29: 230-240

Zhang C, Tian H Q, Pan S F, Liu M L, Lockaby G, Schilling E B, Stanturf J. 2008. Effects of forest regrowth and urbanization on ecosystem carbon storage in a rural-urban gradient in the Southeastern United States. Ecosystems, 11: 1211-1222

Zhang C, Tian H Q, Chen, G S, Chappelka A, Xu X F, Ren W, Hui D F, Liu M L, Lu C Q, Pan S F, Lockaby G. 2012. Impacts of urbanization on carbon balance in terrestrial ecosystems of the Southern United States. Environ Pollut, 164: 89-101

Zhang C, Tian H Q, Pan S F, Lockaby G, Chappelka A. 2014. Multi-factor controls on terrestrial carbon dynamics in urbanized areas. Biogeosciences, 11: 7107-7124

Zhang C, Chen Y L, Lu D S. 2015a. Mapping land-cover distribution in arid/semiarid urban landscapes with Landsat Thematic Mapper imagery. Int J Remote Sens, 36: 4483-4500

Zhang C, Chen Y L, Lu D S. 2015b. Detecting fractional land-cover change in arid and semiarid urban landscapes with multitemporal Landsat Thematic Mapper imagery. Gisci Remote Sens, 52: 700-722

Zhao L, Lee X H, Smith R B, Oleson K. 2014. Strong contributions of local background climate to urban heat islands. Nature, 511: 216-219 